EESTI NSV TEADUSTE AKADEEIMIA TOIMETISED. VII KÖIDE

BIOLOOGILINE SEERIA, 1958, NR. 4

ИЗВЕСТИЯ АКАДЕМИИ НАУК ЭСТОНСКОЙ ССР. ТОМ VII

СЕРИЯ БНОЛОГИЧЕСКАЯ. 1958, № 4

\title{
PARAXONCHIUM STRIATUM GEN. N. SP. N. (NEMATODA, BELONDIRIDAE) - НОВАЯ СВОБОДНОЖИВУЩАЯ НЕМАТОДА ИЗ ПОЧВЫ ЭСТОНИИ
}

\section{Э. Л. КРАлль}

Представители семейства Belondiridae Thorne, 1939 принадлежат к сравнительно редко встречающимся в почве дорилаимоидным нематодам. Большинство видов этой группы описаны только по некоторым экземплярам, и целый ряд из них пока известен лишь в типическом местонахождении.

Отличительным признаком названного семейства дорилаимоидных нематод является особый мышечный футляр, окружающий заднюю, расширенную часть пищевода. Кроме того, для них характерно необыкновенно сильное суженйе тела в передней его части. В большинстве случаев развит только задний яичник, в то время как передняя половая трубка редуцирована. В семейство входит 7 родов: Belondira, Axonchium, Oxydirus, Swangeria, Nygellus, Dorylaimoides и Nygolaimellus. Семейство явно гетерогенное и перечисленные роды представляют собой весьма дивергированные единицы. По мнению самого автора семейства и входящих сюда 4 родов Г. Торна (Thorne, 1939), эти роды в дальнейшем, несомненно, будут преобразованы в самостоятельные подсемейства. Однако ввиду того, что до настоящего времени они представлены лишь немногими видами, им можно дать только родовые названия.

Виды семейства Belondiridae известны в Европе, Азии, Северной и Южной Америках. В СССР найдены лишь немногочисленные представители этого семейства. Известны находки Axonchium tenuicollis Steiner, 1914 в почве вокруг корней томата в Сочинском, Гудаутском и Батумском районах (Тулаганов, 1937) и A. micans Thorne, 1939 в почве вокруг корней ржи в Белоруссии (Мержеевская, 1953).

Следует отметить, что описанное Кирьяновой (1951) в Средней Азии и найденное потом в Эстонии (Кралль, 1957) семейство Opailaimidae систематически близко примыкает к семейству Belondiridae.

При изучении фауны нематод картофеля в Эстонии в почве картофельного поля недалеко от города Тарту нами был обнаружен новый вид семейства Belondiridae. В дальнейшем оказалось, что данный вид является представителем нового рода этого семейства. Ниже приводится описание нового рода и вида.

Paraxonchium gen. $\mathrm{n}$.

Тело дорилаимоидное, цилиндрическое, очень тупое. Латеральные поля широкие. В передней части тело сильно суживается. Ғубы поэтому маленькие, но хорошо отделены. Копье характерное для рода, короткое, 
широкое, немного серповидное, с очень большим отверстием. Передняя часть пищевода узкая, в середине расширяется сразу, без перетяжки. Задняя расширенная часть пищевода окружена особым муускулистым нежным футляром. Кардия сравнительно недлинная, не проникает глубоко в кишечник. Зато кардиальные железы стоят очень свободно, и образуется маленькая перетяжка между мышечной частью пищевода и средней кишкой. По этому признаку новый род несколько сближается с родом Swangeria, у которого кардия по всей длине не окружена кишкой. Половое отверстие расположено за серединой тела. Яичники па рн ы е, сравнительно короткие, изогнутые. Яйцо маленькое.

Новый род ближе всего стоит к родам Axonchium и Belondira. Отличается от них общим строением тела (тупое), формой копья и величиной его отверстия, парными яичниками, формой хвоста (у названных родов хвост закругленный), строением кардии. От Axonchium отличается еще широкими латеральными полями и тем, что первая часть пищевода не отделяется резко от задней части.

Как правило, у видов Belondiridae первый яичник всегда редуцирован. Из близкого рода известны три вида с парными яичниками. У вида Axonchium magnicollis (Cobb, 1906) Thorne et Swanger, 1936, по мнению Торна (Thorne, 1939), ввиду чрезвычайно длинного пищевода $(\mathrm{b}=2.2)$ может быть только один яичник. Вид недостаточно изучен и требует переописания. Axonchium longicollis (Cobb, 1893) Thorne et Swanger 1936, описанный на островах Фиджи, кроме парных половых органов, сближается с новым родом еще наличием маленьких яиц и широких латеральных полей, но отличается от него общим строением тела, строением копья и формой хвоста. Кроме того, половики здесь длинные и половое отверстие находится перед серединой тела. Уже по мнению самого-Торна, названный вид, вероятно, принадлежит не к роду Axonchium, а представляет собой новый род. По нашему мнению, этот вид все-таки сильно отличается от рода Paraxonchium gen. п. и поэтому не может быть включен в него. A. dudichi Andrássy, 1952 отличается от других видов рода, кроме маленьких размеров, еще очень короткой, имеющей вид бульбуса, задней частью пищевода.

Д и агноз рода: Belondiridae, с характерным тупым телом, своеобразным толстым, немного серповидным копьем с отверстием, достигающим более половины длины копья. Пищевод без перетяжки в середине. Кардия недлинная, имеется расстояние между мускулистой частью пищевода и средней кишкой. Половые органы парные, изогнутые, яйца маленькие. Латеральные поля широкие. Хвост конический. Типичный вид:

Paraxonchium striatum gen. n. sp. n. (Рис. $1-6)$.

Описание:

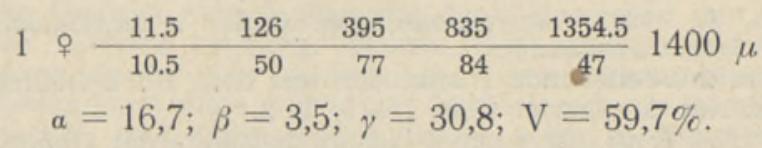

Paraxonchium с общими признаками рода. Тело тупое, незначительно суживается от анального отверстия до начала пищевода. Начиная с заднего конца пищевода, тело постепенно суживается. В передней, узкой части пищевода сужение происходит очень резко, так что диаметр тела на основании губ в 7,3 раза меньше, чем в конце пищевода. Позади анального отверстия тело сначала суживается очень резко с дорзальной и постепенно с вентральной стороны. Затем сужение продолжается постепенно, и конец хвоста конический. На хвосте 6 пар сублатеральных 
папилл. Кутикула покрыта тонкими продольными полосами. Латеральные поля занимают до 1/4 диаметра тела. Қопье длиной 11,5 микрона, очень широкое. Ширина копья составляет $1 / 3$ ширины тела у основания губ. Отверстие его занимает $2 / 3$ длины копья. Расширение пищевода происходит в середине его; мышечный футляр, окружающий заднюю часть пищевода, очень нежный. Задняя кишка длиной анального диаметра, преректум в 1,5 раза длиннее диаметра тела у анального отверстия. Яичники характерные для рода, яйц́ размерами $97 \times 47,5$ микрона. Самец неизвестен.

Д и а н о 3: Paraxonchium с общими признаками рода.

М естонахождени е ти па: 24 июля 1954 г. в Веснери Тартуского района. Найдена одна самка в почве картофельного поля в горизонте от 0 до 10 см. Вид является редким, так как в указанном месте обработана количественная проба в $10 \mathrm{~cm}^{3}$ и вообе обнаружено 698 особей нематод (представителей более чем 30 видов).

Тип сохраняется в нематологической коллекции Института зоологии и ботаники АН Эстонской ССР.

Д р уг и е в и ды: Недавно из Венгрии была описана новая нематода Dorylaimus laetificans Andrássy, 1956, обнаруженная вокруг корней ячменя. Вид описан только по одному самцу и проявляет в общих размерах, є форме копья и т. д. большое сходство с новым видом. Автор этого вида сам считал, что его вид может принадлежать к другому роду (Andrássy, 1956). Однако в названной работе автор не обратил внимания на наличие мышечного футляра вокруг задней части пищевода. Так как у нового рода этот футляр весьма нежен и может легко остаться незамеченным (нами обнаружен только под иммерсией), мы сначала намеревались перенести вид Андраши в качестве второго представителя в новый род Paraxonchium. По письменному сообщению доктора И. Андраши (Будапешт) - за которое мы приносим ему благодарность, - им позднее была обнаружена самка вида $D$. laetificans, а сам вид отнесен к другому роду семейства дорил а и и д (не белондирид!), а именно, к роду Aporcelaimus. От вида Андраши описываемый здесь вид отличается еще формой хвоста, другим расположением хвостовых папилл и длиной изогнутых частей яичников.

Автор считает своим долгом выразить благодарность старшему научному сотруднику Зоологического института АН СССР Е. С. Қ и р в я ов о й за ознакомление с материалом настоящей работы и ценные указания.

\section{ЛИТЕРАТУРА}

К и р в яно в а Е. С., 1951. Нематоды почвы хлопкового поля и целины в Голодной степи (Узбекистан). Тр. Зоол. ин-та, т. IX, вып. 2.

М ер же евская О. И., 1953. Нематоды. главнейших полевых культур БССР. Минск.

Тулаганов А. Т., 1937. Фауна нематод томата и окружающей почвы. Тр. УзГУ, т. VIII. Самарканд.

A n d r á s s y, I., 1952. Freilebende Nematoden aus dem Bück-Gebirge. Annal. Hist.Nat. Mus. Nat. Hungarici (Ser. Nov.), T. 2.

A n d r á s s y, I., 1956. Eine interessante Nematodenfauna der Gerste. Nematol. Notizen 4. Acta Zool. Acad. Sci. Hungariae, T. 2, Fasc. 4.

Andrássy, I., 1958. Erd- und Süsswassernematoden aus Bulgarien. Acta Zool. Budapest. (Цитируется по письменному сообению автора.)

Kra 11, E., 1957. Mõningaid huvitavaid nematoodide leide Eesti NSV pinnasest. ENSV TA Toim., Biol. Seer. 6(3).

Thorne, G., 1939. A Monograph of the Nematodes of the Superfamily Dorylaimoidea. Capita Zool. 8(5). 


\title{
PARAXONCHIUM STRIATUM GEN. N. SP. N. (NEMATODA, BELONDIRIDAE) - UUS VABALTELAV NEMATOOD EESTI PINNASEST
}

\section{E. Krall}

\section{Resümee}

Artiklis kirjeldatakse liiki Paraxonchium striatum gen. n. sp. n., mida on leitud Tartu lähedalt kartulipõllu pinnasest.

Perekonna Paraxonchium gen, n. di a g n o os: Belondiridae, iseloomuliku tömbi kehaga; omapärase laia veidi sirpja suuogaga, mille avaus ületab poole oga pikkusest. Söögitoru laienemine keskosas toimub ühtlaselt. Kardia lühike, kuid üleminek söögitoru lihaselisest osast kesksoolde ei ole pidev. Munasarjad paarilised, käändunud, munad väikesed. Küljeväljad laiad. Saba kooniline.

Tüüpiline liik Paraxonchium striatum gen. n. sp. n., mille kirjeldus vastab perekonna kirjeldusele.

T ü ü bi leiukoht: 24. juulil 1954 Tartu rajoonis Vesneris kartulipöllu pinnases, horisondis $0-10 \mathrm{~cm}$. Leitud $1 \stackrel{9}{\circ}$, mis säilitatakse glütseriin-želantiinpreparaadina ENSV TA Zooloogia ja Botaanika Instituudis.

Nagu teisedki selle sugukonna esindajad, näib liik olevat väga haruldane, sest $10 \mathrm{~cm}^{3}$ suurusest kvantitatiivsest proovist leitud ja analüüsitud 698 nematoodi hulgas leidus vaid üks isend.

\section{PARAXONCHIUM STRIATUM GEN. N. SP. N. (NEMATODA, BELONDIRIDAE) - EIN NEUER FREILEBENDER ERDNEMATODE AUS ESTLAND}

\author{
E, Krall
}

\section{Zusammenfassung}

Ein neuer Nematode, Paraxonchium striatum gen. n. sp. n. aus der Erde eines Kartoffelfeldes in Estland, wird im Artikel beschrieben und abgebildet.

Die neue Gattung Paraxonchium gen. n. ist den Gattungen Axonchium und Belondira systematisch am nächsten verwandt. Sie weicht von diesen jedoch durch folgende Merkmale ab. Der Körper ist sehr plump; die Form des Mundstachels und die Grösse seiner Offnung sind abweichend. Die Ovarien sind paarig entwickelt, die Schwanzform ist eine andere. Kardia ist anders gestaltet. Von Axonchium weicht die neue Gattung noch durch das Vorhandensein der breiten Lateralfelder und des nicht eingeschnürten Oesophagus ab.

Bei der nahestehenden Gattung Axonchium sind drei Arten bekannt, deren Ovarien als paarig beschrieben worden sind. Axonchium magnicollis (Cobb) Thorne et Swanger, 1936 ist ungenügend bekannt. Wegen der langen Speiseröhre $(\mathrm{a}=2,2)$ kann diese Art wahrscheinlich nicht paarige Ovarien besitzen (Thorne, 1939). Axonchium longicollis (Cobb) Thorne et Swanger, 1936 ähnelt der neuen Art ausser der paarigen Ovarien noch in Hinsicht der kleinen Eier und breiten Lateralfelder. Schon nach Thorne's Meinung (Thorne, 1939) gehört diese Art wahrscheinlich nicht der Gattung Axonchium, sondern einer neuen Gattung an. Nach der Meinung des Verfassers kann diese Art wegen der Unterschiede im allgemeinen Körperbau, in der Stachel- und Schwanzform jedoch nicht in die neue Gattung Paraxonchium gen. $\mathrm{n}$. eingereiht werden. Ausserdem besitzt $A$. longicollis lange Ovarien und die Genitalöffnung befindet sich vor der Körpermitte. Die dritte Art mit paarigen weiblichen Gonaden A. dudichi Andrássy, '1952 unterscheidet sich von anderen Arten dieser Gattung ausser der winzigen Gestalt noch durch den sehr kurzen bulbusartigen Oesophagusendteil.

Gattungsdiagnose: Belondiridae, mit charakteristisch plumpem Körper, eigenartigem breitem Mundstachel, dessen Öffnung mehr als eine halbe Stachellänge beträgt. Der Oesophagus ist in der Mitte ohne Einschnürung. Kardia nicht lang, die Kardialdrüsen stehen sehr frei. Es ist eine kleine Distanz zwischen dem muskeligen Teil des Oesophagus und dem Mitteldarm vorhanden (bei der Gattung 
Swangeria ist diese Distanz ausserordentlich lang). Geschlechtsorgan paarig entwickelt. Ovarien kurz, mit Umschlägen. Eier klein. Lateralfelder breit. Schwanz konisch.

G e n e r otypus: Paraxonchium striatum gen. n. sp. n. (Abb. 1 1-6). Der Körper ist auffallend plump, er verjüngt sich von der Analöffnung bis zum Hinterende des Oesophagus nur sehr wenig. Vom Hinterende des Oesophagus an verjüngt der Körper sich mässig, von der Oesophagusmitte an bis zum Vorderende ausserordentlich stark, so dass der Körper beim Oesophagusende schon 7,3-mal breiter ist als der Kopf. Hinter der Analöffnung verschmälert der Körper sich stark dorsal und gleichmässig ventral. Von der Schwanzmitte an verschmälert sich der Schwanz allmählich und endet in einer kurzen konischen Spitze. Auf dem Schwanz befinden sich 6 Paare sublaterale Papillen. Die Kutikula ist zart längsgestreift. Die Lateralfelder sind breit (bis $1 / 4$ des entsprechenden Körperdurchmessers). Der Mundstachel ist 11,5 $\mu$ lang und sehr breit. Sein Durchmesser beträgt etwa $1 / 3$ des entsprechenden Körperdurchmessers und die Offnung ist $2 / 3$ der Stachellänge lang. Kleiner Führungsring vorhanden. Der Oesophagus erweitert sich in der Mitte; die Muskularschicht (muscular sheath), die den hinteren Teil des Oesophagus umgibt, ist sehr zart. Die Rectumlänge ist dem Analdurchmesser des Körpers gleich, das Prärectum ist 1,5-mal länger als der Analdiameter. Die Ovarien sind charakteristisch für die Gattung, beinahe bis zur Vulva zurückgeschlagen. Das Ei $97 \times 47,5 \mu$.

Typischer Fundort: Vesneri (Umgebung von Tartu) in Estland. Die Art wurde am 24. Juli 1954 im Boden auf einem Kartoffelfeld gesammelt (im Horizont von 0 bis $10 \mathrm{~cm}$ ). Es ist eine selten vorkommende Art, denn es wurde in einer quantitativen Probe von $10 \mathrm{~cm}^{3}$ nur ein Weibchen gefunden. Aus dieser Probe kamen überhaupt 698 Nematoden hervor, die mehr als 30 Arten angehörten. Der Typus befindet, sich in der Kollektion des Institutes für Zoologie und Botanik der Akademie der Wissenschaften der Estnischen SSR (Glycerin-Gelatinepräparat).

A ndere A rten: Ganz neulich wurde von Andrássy (1956) in Ungarn eine neue Nematodenart Dorylaimus laetificans Andrássy, 1956 beschrieben. Es ist nur ein einziges Männchen dieser Art gefunden worden. Die genannte Art ist in gewissen Merkmalen unserer neuen Art sehr ähnlich. Sie hat einen verhältnismässig plumpen Körper $(\mathrm{a}=24,8)$; auch die anderen Ausmasse stimmen mit denen unserer Art gut überein. Der eigenartigen Stachelform, den freistehenden Kardialdrüsen und einigen anderen Merkmalen nach sind beide Arten gleichfalls ähnlich. Andrássy (1956) selbst vermutet, dass es sich hier nicht um eine Dorylaimus-Art handelt, sondern um einen Vertreter einer neuen Gattung. Leider erwähnt er nicht die IMuskularschicht, die bei unserer Art den Hinterteil des Oesophagus umgibt. Man muss aber bemerken, dass diese Schicht bei der neuen Gattung schwach entwickelt und überaus zart ist. Deshalb konnte sie eventuell auch unbemerkt bleiben. So wollte ich denn auch die von Andrássy beschriebene Art anfangs als einen anderen Vertreter in die neue Gattung einreihen. Nach freundlicher Mitteilung von Dr. I. Andrássy (Budapest) hatte er später auch Weibchen D. laetificans gefunden, diese Art selbst aber in eine andere Gattung der Dorylaimiden (nicht Belondiriden), und zwar in die Gattung Aporcelaimus eingereiht. Unsere Art weicht von der ungarischen auch durch ihre abweichende Schwanzform, eine andere Anordnung der Schwanzpapillen und die Länge der zurückgeschlagenen Teile der Ovarien wohl ab.

Institut für Zoologie und Botanik

der Akademie der Wissenschaften der E'stnischen SSR
Eingegangen am 19. Juni 1958 